\title{
Economies of scale and scope in Australian urban water utilities
}

\author{
Andrew C. Worthington ${ }^{*}$, Helen Higgs \\ Department of Accounting, Finance and Economics, Griffith University, QLD 4111, Brisbane, Australia
}

\begin{abstract}
This paper estimates economies of scale and scope for 55 major Australian urban utilities over the period 2005/06 to 2008/09. The models used specify operating and capital costs as a function of chemical and microbiological compliance, water losses, water quality and service, water main breaks, total connected properties, and urban water supplied. The input variables used to help determine water utility costs include the density of properties served and the sourcing of water from bulk suppliers, groundwater, recycling and surface water. In terms of economies of scale, the evidence suggests strong economies of scale at relatively low levels of output (50-75\% of current mean output). In terms of product-specific economies of scale (increasing the scale of a specific output in isolation), there is substantially stronger evidence that the operating costs of urban water utilities would benefit from increasing scale with regard to chemical compliance, water quality and service complaints, and the number of connected properties. In contrast, capital costs would benefit from scale increases with regard to the management of water losses and water main breaks. For economies of scope, it is clear that there are substantial cost benefits from the joint production of treated quality water delivered across a network with minimal water losses and main breaks. The main cost advantage at all levels of output is decreasing water losses, and this would benefit both operating and capital costs.
\end{abstract}

Keywords:

Economies of scale

Economies of scope

Urban water utilities

Australia

The first-named author gratefully acknowledges the funding of a 2010 National Water Commission (NWC) Research Fellowship, with an earlier version of the paper appearing in a report prepared for the NWC entitled "Productivity, Efficiency, and Technological Progress in Australia’s Urban Water Utilities” (Worthington, 2011b). The authors would like to thank the editor, two anonymous reviewers, and seminar participants at the NWC, the University of South Australia, and Lancaster University for helpful comments and suggestions.

\footnotetext{
* Corresponding author. Tel.: +61 7 37357371; fax: +61 737353719.

E-mail addresses: a.worthington@griffith.edu.au (A.C. Worthington), h.higgs @griffith.edu.au (H. Higgs).
} 


\section{Introduction}

A number of factors have combined to reignite global interest in water policy as it relates to urban water utilities in the 21st century. Starting from their essential nature as natural monopolies, operating as utility or network industries with similar treatment and delivery systems, countries around the world have progressively evolved very different approaches to providing urban water services, especially in the mix of privately and publicly owned entities and the extent of regulatory intervention to govern pricing and standards. However, recent circumstances, however, have added impetus to these longstanding developments. These include declining rainfall associated with climate change; pressing needs for maintaining and expanding expensive water supply infrastructure; jurisdictional, sectoral and environmental conflicts over existing surface and groundwater supplies; the expansion of supply options to include recycling, desalination, stormwater and managed aquifer recharge; the adoption of water recycling programs, and rapid population growth and urbanisation. In response, governments worldwide, including in Australia, have refocused on improving the efficient management and delivery of urban water services.

Apart from sharing these developments through the recent catalyst of the National Water Initiative, perhaps one of the most defining features of Australian urban water utilities is the considerable variance in their scale (size) and scope (diversity of outputs). This is an outcome of two separate processes. First is the evolution of the urban water utility sector in this country into sometimes very large (regional and intraregional), publicly owned, corporatized water utilities operating under regulated prices. Second is the continuance of existing arrangements for small water and sewerage utilities owned by local councils operating without formal independent price regulation but with some assurances that water services are independent of other council functions. Consider first the different scales of operation. At the wholesale water level, the Australian Capital Territory (ACT), the Northern Territory and South Australia each have a single urban bulk water supplier; NSW has two; Tasmania and Victoria both have three; Queensland several; and about twenty operate in Western Australia. Of these, some are responsible only for urban water, which may or may not be the same entity engaged in the downstream retail business, while others are responsible for both rural and urban bulk water businesses.

A similar picture emerges at the retail level. Here, urban water services are sometimes very highly concentrated (as in the ACT, Northern Territory and South Australia), whereas Victoria has three metropolitan and 13 regional urban retail businesses; NSW and Queensland each have over time three or fewer businesses centred on their largest population centres (Sydney and Southeast Queensland) and more than 100 local government or other suppliers. Even among the 73 largest urban water suppliers considered for this analysis, there is an astonishing variability in size, with 
businesses serving anywhere between ten thousand and 1.7 million households (the several hundred smaller utilities in Australia serve anything from a few hundred to a few thousand households). As for scope, there is very little alignment between urban water supply and urban water drainage services, with most stormwater and drainage services remaining the responsibility of local governments or only the very largest urban water utilities. Putting this aside, there is again a wide range of behaviour with many utilities providing both water and sewerage services, and a few water or sewerage services only.

Clearly, the substantial variation in the scale and scope of Australia's urban water utilities suggests the potential for economies of scale and scope to impact upon efficient outcomes and thereby provide inferences concerning, among others things, industry practice and the impact of regulation and future industry structure (Fraquelli et al., 2004; Fraquelli and Moiso, 2005). Unfortunately, very few studies of the efficiency of Australia's urban water utilities are known (Woodbury and Dollery, 2004; Coelli and Walding, 2006; Byrnes et al., 2010, Worthington, 2011a, 2011b). This is a particularly glaring omission in that urban water regulators elsewhere, especially the UK, have made substantive use of efficiency-based techniques in guiding policy (Ofwat, 2010a, 2010b 2010c). Moreover, none of these concern estimation of economies relative to scale using the widest sample possible from throughout Australia (Worthington, 2011b; Abbott and Cohen (2009a, 2009b) provide a useful general discussion of urban water utility issues, including in Australia). Accordingly, the purpose of this paper is to estimate economies of scale and scope for Australian urban water utilities.

The paper is divided into four main sections. Section 2 briefly discusses the nature of costs in urban water utilities and the theoretical and conceptual sources of any economies of scale and scope. Section 3 deals with the specification of costs and outputs. Section 4 focuses on the cost function specification used to estimate economies of scale and scope herein and Section 5 presents the results. The paper ends with some concluding remarks in the final section.

\section{The nature of economies of scale and scope in urban water}

In general, we can divide the costs (expenditure) required to operate an urban water utility into two main areas: operating costs and capital costs. We broadly define operating expenditure as the day-to-day expenditure incurred by the water utility in managing its business, while capital expenditure relates to those amounts typically invested in long-lived assets and depreciated over time. Using the NWC's (2010a) indicators and definitions handbook, operating costs (operation, maintenance and administration) typically include the following: water resource access charges or resource rent taxes (paid by the utility); purchases of raw, treated or recycled water; salaries and wages; overheads on salaries and wages; materials, chemicals, and energy; contracts; and 
accommodation. They also include items expensed from work in progress (capitalized expense items), pensioner remission expenses, and competitive neutrality adjustments; they may also include but are not limited to, land tax, debits tax, stamp duties and council rates. In contrast, and again using the NWC's own definitions, capital expenditure includes all expenditure for new works, renewals or replacements, other expenditures that would otherwise be referred to as capital, and assets devoted to water recycling.

Importantly, as in most other business, external parties will almost universally handle some of the services associated with these expenditures, whereas others lie along a spectrum of in-house and external third-party providers. For example, NWC (2010a) highlights the role of 'alliance' contracts (used to deliver operations and maintenance work, customer service, or capital expenditure activities) as an increasingly prevalent feature of water utility operations in Australia. While individual alliance contracts differ, they typically involve an agreement between the water utility and an alliance partner(s) with regard to the reimbursement by the utility of the alliance partners' direct and indirect expenses, usually including an agreed upon profit margin; a transparent forecast of expenditures on capital or operating programs is also commonly agreed upon in advance. Alliance arrangements also include reporting from the alliance partners to the utility once programs are underway, along with the sharing of any cost savings or overruns between the utility and its alliance partners (NWC, 2010a).

The actual behavioural stance water utilities take to these expenditures, both operating and capital, is potentially difficult to conceptualise. Australia's urban water utilities are mainly commercialized public-sector entities operating in highly regulated quasi-markets. Nonetheless, there is often an expectation of profitability by the (government) owners, in terms of dividends paid. As argued by the NWC (2010a), the level of dividends payable will reflect government dividend and pricing policies, the profitability of the utility, and its future cash requirements. Nevertheless, government generally sets dividend policy and it is often outside the direct control of the individual utility, even though the utility retains the capacity to set prices, etc. (though limited as a regulated monopoly). In addition, we typically only observe a stable dividend policy in the very largest water utilities, often with very high payout ratios, while in practice few of the smaller water utilities pay dividends at all. Clearly, we cannot blindly apply a profit-maximising objective across the sector. However, one acceptable long-run cost objective for water utilities is to be in a position to produce the desired output (or outputs), either stipulated by regulation and/or required by customers, at the lowest possible cost (or cost minimisation). This minimal performance criterion should apply to any economic enterprise desiring the efficient use of resources.

As discussed in Worthington (2014), the principal outputs for most urban water utilities would appear to be the quantity and quality of water produced and distributed and the number of 
customers served in the distribution network. Efficient production would then entail, among other things, adjusting the scale of production to the most appropriate size for the outputs produced. Sometimes dividing the production process into smaller more specialized production units can result in operating economies, as evidenced by the division of most urban water utilities into separate departments responsible for water and sewerage services. Other times, this will be the division into entirely different entities operating with or without physical interconnection (in practical terms, the potential for exploiting scale economies will always be larger with the former). On other occasions, enlarging the scale of production can achieve lower unit costs. This can proceed over time through a continuum ranging from the internal provision of services to full contracting out. These arrangements can help water utilities overcome indivisibilities in factor inputs, address the lack of capacity, and gain access to economies in the costs of production, including purchasing, marketing and administration (such as human resources and information technology). Of course, it is equally possible that diseconomies of scale can arise. These include the increase in input prices as industry constraints on factor availability apply (for example, the bidding up of the price of specialised labour) as well as the reduction of incentives and effective coordination through the growth of bureaucracy and organisational complexity in large organisations. From a pure engineering viewpoint, there are additional complexities in urban water utilities relating to the often less-than-proportional increase in production from larger plants and in distribution from larger pipes and pumping stations, the limits of system size, and the problems associated with renovating large urban distribution systems.

Once multiple output production arises, the presence or absence of cost complementarities among outputs in (joint) production also becomes important. In the case of water utilities, the production process typically comprises multi-product attributes because multiple products are produced (for example, various qualities and quantities of potable water and different water and sewerage services) through the sharing and joint utilisation of inputs. These include management and administrative labour, information technologies, human resources, piping networks and access, technical knowledge, and so on. This diversity of outputs, known as 'scope,' may provide cost advantages in that a single water utility producing a given level of several outputs may spend less per unit than a combination of several specialised utilities focusing on a specific output. We can see this especially clearly in the water utility literature where outputs typically include the volume of water (Norman and Stoker, 1991; Thanassoulis, 2000; Anwandter and Ozuna, 2002; Tupper and Resende, 2004; Coelli and Walding, 2006; Byrnes et al., 2010) and the number of connected properties (Coelli and Walding, 2006; Saal and Parker, 2006; García-Valiñas and Muñiz, 2007). However, they also can include the length of mains or the service area (Thanassoulis, 2002; Munisamy, 2010), the average pumping head, the proportion of non-residential customers served, 
and indexes based on water-quality assessments, service outages, and customer complaints (Woodbury and Dollery, 2004; Byrnes et al., 2010).

Of course, in many cases we simply cannot envisage the situation where specialised utilities could provide these outputs separately. This is easy enough with a utility providing both water and sewerage services, and even possibly stormwater services, where most studies assume sizeable economies of scope from joint production in the sharing of various types of labour, pipe-laying machinery, recycling technology, and so on. However, given the network nature of urban water utilities, we have some difficulty imagining one utility delivering the quantity of water and another delivering quality. We could more readily accept one producing water (as a bulk supplier) and another distributing it, or separate responsibilities for wholesale, commercial, and retail distribution or for operation and maintenance of the network. However, in any estimation we would usually wish to include several dimensions of output, if only to ensure that we have fully specified its nature and qualities to avoid any possible misspecification bias.

\section{Specification of outputs and costs}

The data consist of annual observations of 55 major Australian urban utilities over the period 2005/06 (the year of the first National Performance Report) to 2008/09 (NWC 2008, 2009, 2010b). This is longest period where the Water Services Association of Australia, in conjunction with the National Water Commission and the parties to the National Water Initiative (the Commonwealth of Australia and the governments of NSW, Victoria, Queensland, South Australia, ACT, Northern Territory, Tasmania and Western Australia), have provided consistent utility-level data. Unfortunately, the data for 2009/10 were not available at the time of the analysis. In the 2008/09 report, 73 utilities from across Australia supplying approximately 17.2 million Australians with their water services provided the some 117 indicators used in the report. These indicators cover a wide range of critical performance areas, including safety (health), customer service, asset management, environmental, finance, and pricing.

In terms of sampling, we first removed all utilities where data was unavailable for each year over the three-year period. We then removed an additional 18 reporting water utilities from the sample. To start with, we excluded the seven bulk water suppliers (Fish River Water, Goldenfields Water, Rous Water, Sydney Catchment Authority, Seqwater, Hobart Water, and Melbourne Water) because their productive behaviour differs substantially from most other utilities. Bulk utilities are utilities that do not have retail end-use customers of their own; instead, they provide wholesale services to other water utilities. These services potentially include the harvesting and storage of water in reservoirs, the treating and transferring water from storage to other reticulation networks, and the treating and disposing of (or recycling) of sewage collected from other customers. That 
said, eliminating bulk water suppliers carries with it the risk we are omitting that part of the urban water cycle where significant returns to scale are thought to exist: namely, in the headworks and transmission network. Indeed, there is no physical network delineation between bulk suppliers and retailers in any practical sense. Including the data on bulk water suppliers in the analysis could address this. Unfortunately, there is no correspondence between the variables available for bulk water suppliers and those specified in this analysis.

Given the range of operational structures, with most utilities providing both water and sewerage services and a few only water or sewerage services, we remove institutions offering sewerage services only (including Wagga Wagga Council, Riverina Water, City of Kalgoorlie-Boulder, and Water Corporation-Bunbury). Fortunately, as the indicators in the data are split according to water and sewerage services, we were able to retain utilities offering water services only and utilities offering both water and sewerage services. Finally, we removed seven other utilities with missing data that we could not extrapolate, reconstruct, or approximate from the data available. One indicator of the scale of missing data is that in the 2006/07 report, the amount of available data was about $60 \%$ of the total potential dataset, rising to $80 \%$ in $2007 / 08$ and $85 \%$ in $2008 / 09$. This necessarily determined both the sample composition and the specification of inputs and outputs with a view of maximising the sample size. Table 1 lists the 55 utilities included in the analysis along with their location by jurisdiction (state) and the categorisation in the report by the number of connected properties.

\section{$<$ TABLE 1 HERE $>$}

Stochastic cost functions typically regress costs (here separated into operating and capital expenditure) on the quantity and price of the factor inputs used in production (typically capital and labour) and the outputs produced (Fabbri and Fraquelli, 2000; Filippini et al., 2008). Unfortunately, the data released by the NWC in its reports do not permit full specification of the prices and quantities of the factor inputs. A suitable cost function would then typically specify the quantity of labour employed (where the price is the average wage or salary) along with the amount of energy and chemicals used (average price paid) and some measure of physical capital (such as dollar value of physical assets, where the price is the rate of depreciation). See, for example, Norman and Stoker (1991), Bhattacharya et al. (1995), Aubert and Reynaud (2005), Kirkpatrick et al. (2006), Da Silva e Souza et al. (2007), and Bottasso and Conti (2009)]. As these data are not available, we effectively assume that input prices are constant across the industry and so the quantity of factor inputs employed in production is proportional to the quantity of operating and capital expenses. Fortunately, Australian urban utilities are arguably price-takers operating in competitive factor markets, at least in terms of labour and financial capital. However, we do include a number of non- 
price variables that help determine input prices in our specification to account for variation across water utilities.

While we should attempt to model the determination of operating and capital costs separately, not least because they are a function of different parameters, information on capital expenditure and the written-down replacement cost of fixed water supply assets is available only for the most recent report (2008/09). For this reason, we estimate three separate cost functions. The first specifies total operating cost (\$000) (Australian dollars) as the dependent variable as a function of seven outputs:

CHC: the percentage of zones where chemical compliance was achieved (\%);

MBC: the percentage of zones where microbiological compliance was achieved (\%);

LSI: the inverse of real losses (L/service connection/d);

WQI: the inverse of water quality and service complaints (per 1,000 properties);

WMI: the inverse of water main breaks (per $100 \mathrm{~km}$ of water main);

PRP: total connected properties (000s); and

WTR: total urban water supplied (ML).

This is reasonable in that the literature generally accepts these parameters are drivers of water utility costs and that our focus is not utility-level efficiencies, rather sector wide economies of scale and scope. We also specify five input variables that help determine water utility costs:

PNM: properties served per km of water main (n);

BLK: the percentage of water from bulk suppliers (\%);

GRD: the percentage of water from groundwater (\%);

REC: the percentage of water from recycling (\%); and

SUR: the percentage of water from surface water (\%).

Because of the lack of data, we specify this operating cost function over the period 2005/06 to 2008/09. The upper panel in Table 2 provides selected descriptive statistics.

\section{<TABLE 2 HERE $>$}

The second and third cost functions only use data from 2008/09 when information on capital expenditure and the amount of physical capital is available. The lower panel in Table 2 provides selected descriptive statistics. Accordingly, we attempt to specify more finely those parameters that determine operating costs from those that determine capital costs. The first model specifies total operating expenses (\$000) (OXT) as a function of four outputs (CHC, MBC, WQI and PRP) and five input variables (PMN, BLK, GRD, REC and SUR). The second model specifies total capital cost (\$000s) (CXT) as a function of four outputs (LSI, WMI, WTR and PRP) and five input variables (CAP, BLK, GRD, REC and SUR). In general, the first model regards operating costs as a 
function of water quality, the number of supplied properties, the sources of water the utility employs and the associated requirements for treatment, and the density characteristics of its service area. The focus is short-run, day-to-day operating demands of customers. The second model instead focus on capital expenditure and the efforts the utility takes to expand and maintain a network that minimize water losses and breaks relative to the amount of water supplied and the size of the utility, the amount of capital already invested, and the infrastructure needs of its water resources. The focus is then largely the long-run asset requirements of the utility system.

However, the capital expenditure specification is problematic in that while there is a good correspondence between depreciation and maintenance costs for the existing capital stock, there is no allowance for the expansion of existing capital stock to service urban growth in the future. This is important in that urban water utilities are required to plan and provide water infrastructure prior to development. For this reason, we would need to exercise some caution when evaluating individual utility cost outcomes, especially for those with rapidly growing networks. Similarly, overall and in many individual utilities, water usage is declining due to efficiency measures, changes in household consumption preferences, and in some cases, stagnant or declining populations. This may infer the need for the contraction of the existing capital stock, were it even politically and economically feasible. Clearly, expected growth (or the lack of growth) is an important dynamic that we are unable to address using a single year of data.

\section{Model specification}

We employ a quadratic cost function to estimate these models. This has the advantage of a flexible specification applicable to multifactor production. The cost function is also an appropriate form to take account of the linear, quadratic, and cross product terms found with more than one output. A cost function that allows the economies of scale to vary with different levels of input, $x_{\mathrm{i}}$ and output, $y_{\mathrm{i}}$ is specified as:

$$
C=\alpha_{0}+\sum_{i=1}^{m} \alpha_{i} y_{i}+1 / 2 \sum_{i=1}^{m} \beta_{i}\left(y_{i}\right)^{2}+\sum_{\substack{i, j=1 \\ i \neq j}}^{m} \delta_{i j} y_{i} y_{j}+\sum_{i=1}^{n} \gamma_{i} x_{i}+\varepsilon_{i}
$$

where $\alpha_{0}$ is the fixed cost term, $\alpha_{i}(i=1,2,3, \ldots \mathrm{m})$ are the slope coefficients of the linear term for all outputs $y_{\mathrm{i}}(\mathrm{i}=1,2,3, \ldots \mathrm{m}), \beta_{i}(i=1,2,3, \ldots \mathrm{m})$ are the slope coefficients of the quadratic terms, $\delta_{i j}(i=1,2,3, \ldots \mathrm{m}, j=1,2,3, \ldots \mathrm{m}$ and $i \neq j)$ are the slope coefficients of the cross-product terms, $\gamma_{\mathrm{i}}(i=1,2,3, \ldots \mathrm{n})$ are the coefficients of the linear term for all inputs $x_{\mathrm{i}}(i=1,2,3, \ldots \mathrm{n})$ and $\mathrm{C}$ is alternately the total operating (OXT) or capital (CXT) costs of each water utility.

The cost function in (1) allows the estimation of economies of scale and scope. We define these as ray economies of scale, product-specific economies of scale, global economies of scope, and 
product-specific economies of scope. Under ray economies of scale, we assume the composition of each utility's output remains fixed while the aggregate quantity of output varies. This provides a measure of scale analogous to the single output case where ray economies (diseconomies) of scale exist if the measure is greater (less) than unity. Product-specific economies of scale allow one output to vary, holding all other outputs constant; these economies (diseconomies) exist if the measure is greater (less) than unity. With global economies of scope, we again assume the composition of each utility's output remains fixed while the aggregate size of output varies. Finally, product-specific economies of scope measure whether the cost of producing the outputs jointly is less than the costs of producing them separately. A value greater than or equal to zero thus indicates that cost advantages accrue through the joint production of outputs.

The method for calculating these measures is as follows. First, the average incremental cost, $\left.A I C\left(y_{i}\right)\right)$ for producing output $y_{i}$ is defined as:

$$
\operatorname{AIC}\left(y_{i}\right)=\frac{C(y)-C\left(y_{N-i}\right)}{y_{i}} \quad i=1,2,3, \ldots \mathrm{m} .
$$

where $C(y)$ is the total cost of producing the four outputs and $C\left(y_{N-i}\right)$ is the total cost of producing zero units of the $i$ th output. In the case of a single product, we measure the economies of scale using the average incremental cost divided by the marginal cost. The product-specific economies of scale for $y_{i}, E\left(y_{i}\right)$ are specified as:

$$
E\left(y_{i}\right)=\frac{\operatorname{AIC}\left(y_{i}\right)}{M C\left(y_{i}\right)}
$$

where $M C\left(y_{i}\right)=\partial C / \partial y_{i}$ is the marginal cost of producing $y_{i}$ units of output. Ray economies of scale exist when the quantities of the product increase proportionately, defined as:

$$
E(R A Y)=\frac{C(y)}{\sum_{i=1}^{m} y_{i} \times M C\left(y_{i}\right)}
$$

If $E\left(y_{i}\right)$ or $E(R A Y)$ is greater than one (less) than one then economies of scale (diseconomies of scale) exists for output $y_{i}$. Second, we can divide economies of scope into global economies of scope (GES) and product-specific economies of scope $(S)$, defined as:

$$
\operatorname{GES}\left(y_{i}\right)=\frac{\sum_{i=1}^{m} C\left(y_{i}\right)-C(y)}{C(y)}
$$

Finally, we calculate the product-specific economies of scope using: 


$$
S\left(y_{i}\right)=\frac{C\left(y_{i}\right)+C\left(y_{N}\right)-C(y)}{C(y)}
$$

\section{Results}

Table 3 presents the estimated coefficients and standard errors of the three quadratic cost functions: namely, operating expenditure for 2005/06-2008/09 in columns 2-4, operating expenditure for 2008/09 in columns 5-7, and capital expenditure for 2008/09 in columns 8-10. The table also include $\mathrm{R}^{2}$ as a measure of goodness-of-fit and the F-statistic of the null hypothesis that the slope coefficients are jointly zero. To start with, it is obvious that the models will inevitably include multi-collinearity as the explanatory variables contain a linear combination of outputs together with squared and cross product terms. Accordingly, it is generally difficult to interpret the estimated slopes for the individual coefficients.

\section{<TABLE 3 HERE>}

The values of $\mathrm{R}^{2}$ in Table 3 indicate that the models explain a significant proportion of the operating and the capital expenditure in the sampled water utilities, ranging from 98.6-99.0\%. We jointly test the null hypotheses of no output effects in addition with various tests of no linear, quadratic and output cross-product effects with Chi-squared test statistics (statistics not shown in the table). We reject all hypotheses at the $1 \%$ level of significance, indicating that all of the explanatory variables (including their squares and cross products) should be included when estimating operating and capital cost functions for Australian urban water utilities.

The estimated quadratic cost functions in Table 3 are used to estimate the marginal costs (MC) and average incremental costs (AIC) for each of the water utility outputs for levels of mean output from $50 \%$ to $300 \%$ (i.e., $100 \%$ is the mean output in the sample data) in Table 2 . For instance, over the period 2005/06-2008/09, the mean water utility had chemical compliance (CHC) of 89.70\%, microbiological compliance (MBC) of 95.58\%, inverse water losses per connection per day (LSI) of 1.61 (62.2 litres per connection per day), inverse water quality and service complaints (per 1,000 properties) (WQI) of 25.83 (3.87 complaints per 1,000 properties), inverse water main breaks (per $100 \mathrm{~km}$ of water main) (WMI) of 8.64 (11.57 breaks per $100 \mathrm{~km}$ of water main), and 127.53 thousand total connected properties.

\section{$<$ TABLE 4 HERE $>$}

Consider the marginal costs of operations over 2005/06-2008/09 in the upper panel of Table 4. As shown, the marginal cost of microbiological compliance declines from 50-75\% of mean output and from 50-300\% for both water quality and service complaints and the number of connected properties. Interestingly, the marginal cost of an additional connected property for a utility three 
times larger than the mean (\$67.53) is twelve times smaller than a utility with only $50 \%$ of the mean number of connected properties (\$843.33). In general, there are decreasing (in fact, negative) marginal costs in the number of water main breaks, chemical compliance and the volume of water delivered and decreasing (positive) marginal costs for the total number of connected properties and water quality and services complaints. Where we split operating and capital expenditure in 2008/09, the marginal costs for operating expenditure are broadly unchanged, while the marginal cost of capital expenditure per connected property is positive but decreasing up to $150 \%$ of mean output and thereafter increasingly negative. A similar picture emerges for the average incremental costs in Table 5.

The negative values for marginal costs in Table 4 are potentially confusing. In theory, if inputs are normal and prices positive, then total variable cost must increase with output, such that marginal cost is always positive. One obvious problem with our analysis is that we were unable to specify individual factors and prices because of the lack of data. Accordingly, the assumption of constant cost over the sector may not hold and this could account for negative marginal costs (i.e., larger water utilities may have substantially lower factor prices than smaller utilities). Putting this aside, there are several other reasons why we may technically observe negative marginal costs.

First, consider the production of treated water. Even if the treatment plant is designed to operate at any level of output, it is unlikely that it can be designed to operate optimally at all levels and at all times. For example, the plant may require additional maintenance when operated at a less than ideal level. The saving in maintenance cost could then outweigh the increased cost of other variable factors required for production closer to the plant's ideal level, resulting in a negative marginal cost (Glustoff and Wickham, 1991). Second, input prices may be negative, especially in the presence of joint production. This is particularly pertinent when considering the specification of outputs in this analysis. For example, by decreasing water main breaks (an increase in WMI) water utilities will also jointly produce lower water losses (an increase in LSI) and potentially fewer water service complaints (an increase in WQI). Similarly, production aimed at improving chemical (CHC) and microbiological (MBC) compliance might lower the number of complaints relating to water quality (an increase in WQI), although it is difficult to imagine the average customer is able to detect even major changes in measures of water quality not directly reflected in the clarity of the water or its taste. Accordingly, the specific factors of production underlying our operating and capital costs (not specified) may have a negative price, thereby also accounting for the estimated negative marginal costs.

$<$ TABLE 5 HERE $>$ 
Table 6 provides the product-specific (E) and ray (RAY) economies of scale for operating and capital costs. As defined earlier, the point estimates represent the degrees of ray economies (diseconomies) of scale; if the point estimate is greater than unity, then ray economies of scale exist across the output set. As shown by the shaded cells, ray economies (the proportional augmentation of output holding composition constant) exist from $50 \%$ to $75 \%$ of the mean output over the sample period for operating expenses in the period 2005/06-2008/09 and for capital costs in 2008/09. This suggests that much of the sector as a whole is currently experiencing economies of scale and there is a clear incentive to expand the production of all outputs at low levels to exploit existing potential scale economies. However, at some level between $75 \%$ and $100 \%$ of current mean output, diseconomies of scale affect operating and capital costs in Australia's urban water utilities when holding the composition of output constant.

\section{$<$ TABLE 6 HERE $>$}

Table 6 also includes the product-specific economies of scale. These are the scale economies that exist were a particular output increased in isolation. As shown for operating costs in the period 2005/06-2008/09, for CHC these are from 75-300\% of mean output, 50-75\% for MBC, 175-300\% for LSI, WQI and PRP, and 200-300\% for WMI. These indicate that water utilities can obtain economies of scale by increasing individual outputs up to very high levels (only calculated to 300\% of current mean output). For capital costs in 2008/09, the evidence suggests that there are productspecific economies of scale for LSI from 225-300\%, from 75-300\% for LSI and at 50\% for WTR. Of course, we must treat the results using the 2008/09 data with care, for although the models potentially reflect better the cost drivers of operating and capital expenditure, we only have a small cross section of observations from which to estimate.

\section{$<$ TABLE 7 HERE $>$}

Table 7 includes the product-specific and global economies of scope. As shown in the upper panel, global economies of scope increase (though at a diminishing rate) from $50-300 \%$ of current mean output. This indicates that there are costs advantages of providing the outputs as specified at all conceivable levels of output. However, the clearer separation of operating and capital costs in the middle and lower panel in Table 7, respectively, indicate that product-specific and global economies of scope prevail in operating costs at relatively low levels (50-75\%). The suggestion is that water utilities do not have to be very large at all before it makes cost sense to produce these outputs in a single physical system (even if it were possible to disentangle, say, water treatment from system maintenance). In contrast, we find global economies of scope in capital costs for all conceivable levels of outputs, but only product-specific economies of scope (again for all conceivable levels of output) in LSI. One implication is that by increasing LSI (lowering the 
amount of water losses) water utilities can decrease costs at all levels of output. Otherwise, they can increase the economies of scope in capital costs by increasing output in its current composition, again at all levels.

\section{Concluding remarks}

This paper employed stochastic functions of operating and capital costs to calculate productspecific economies of scale and scope and ray and global economies of scale and scope, respectively, for 55 major urban water utilities over the four-year period 2005-06 to 2008-09. The section comprised two separate but complementary analyses. The first focused only on scale and scope economies in operating expenditure over the full four-year period 2005-06 to 2008-09. The second analysis considered scale and scope economies in both operating and capital expenditures, but because the recorded replacement cost was only available for 2008-09, it was not possible to accurately specify separate operating and capital-cost equations for the full four-year period. Accordingly, the results for economies of scale and scope in operating expenditure over the whole four-year period are relatively more robust than the single cross section used to evaluate scale and scope economies in operating and capital expenditures for 2008-09 only. Nevertheless, the technique employed incorporates allowance for stochastic variation (mismeasurement, misspecification, unexpected outcomes, etc.) that could potentially arise when using a single year of data.

First, in terms scale, the evidence suggests that there are strong economies at relatively low levels of output for Australian water utilities (up to 75 percent of mean output or about 90,000 connected properties). One implication is that horizontal aggregation will provide efficiency gains, especially if the composite utilities are located in close geographic proximity and if the increase in scale does not require significant investment in system costs. In the sample, 11 utilities are currently too large (experiencing diseconomies of scale) with connected properties in excess of 125,000 properties, while 44 utilities have fewer than 65,000 connected properties of which 25 have fewer than 30,000 connected properties (both experiencing economies of scale). It is important to recall that the sample only includes utilities with at least 10,000 connected properties, and so it seems likely that increasing economies of scale would also prevail for the several hundred smaller water utilities in the Australian population, but not included in this analysis.

In terms of product-specific economies of scale (increasing a single output in isolation), there is evidence that there are scale economies in chemical compliance, water quality and service complaints, and the number of connected properties; that is, the average costs of each of these outputs become lower as output increases. Further, there are product-specific economies of scale in capital costs for water losses and water main breaks; that is, the average costs of reducing water 
losses and water main breaks also become lower as production increases. However, it would appear that these only come about at relatively high levels of output (125 percent and higher) and so are unobtainable for all but the very largest utilities in the sample. Second, in terms of economies of scope it is clear that there is substantial cost advantages in the joint production of the outputs included in this analysis. The presence of scope economies typically provides some support for vertical integration, as here where wholesale water storage and acquisition, treatment, delivery, and retail services are included in single entities. Nevertheless, the focus of this report is on potable water, so we have not considered other economies of scope that potentially exist among potable water, wastewater, and stormwater services.

Of course, the analysis does have a number of limitations and these both qualify the findings and suggest future directions for research. First, the sample only includes the largest urban water utilities in Australia, and while these service the majority of Australian households, the results are not directly reflective of the many hundreds of smaller urban water utilities. Unfortunately, there is no nationally consistent dataset readily available for these smaller entities. An equally important consideration is that the evidence for economies of scale and scope in capital expenditure is less robust than that for operating expenditure, as the former is only able to employ a single year of data (2008-09). This qualifies the interpretation of some of the findings.

Second, while the data we employ are rich, they include much more information on water utility outputs than on inputs. This is most clear in the lack of data on capital expenditures and the amount of physical capital for most of the sample period. For instance, one measure that would be useful would be the quality of the utility's raw (untreated) water, as quality variation largely determines the variation in water treatment, which in turn affects the variation in costs. Renzetti (2001), for example, examined the effect of variation in the quantity and quality of raw water supplies and found that an increase in contamination led to an increase in the cost of treating and supplying a given quantity of output. As we do not have this information, we are obliged to assume that the quality of water is uniform by source and over time, given that we include parameters reflecting the share of raw water sourced from bulk suppliers, groundwater, recycling, and surface water in our costs functions. More generally, the lack of specific input information obscures many of the interesting differences we could potentially identify. For example, Shih et al. (2006) investigated economies of scale for individual cost components and found higher economies of scale in capital, materials, outside services, and other costs, and lower, but still positive, economies of scale in labour and energy costs.

Finally, the focus in this analysis is on potable water services, not water and wastewater services, even though the majority of water utilities in Australia provide both. While it is possible to separate the services provided by water utilities into water and sewerage services, at least as far as 
correctly specifying their respective cost functions based on the available data, it is likely that utilities benefit from the economies of scope between water and sewerage. For example, both are network services and have comparable input requirements. There is also the real potential for the production of one type of output to affect the other. For example, improved treatment of sewage will have benefits for water quality drawn from surface sources, while treated sewage can also provide an input to water services in the form of recycled wastewater. Fortunately, there is an emerging body of literature applying efficiency measurement techniques to wastewater services from which further direction can be obtained [see, for example, Estache and Trujillo (2003), Tupper and Resende (2004), Erbetta and Cave (2006) and Nauges and van den Berg (2008)].

\section{References}

Abbot, M., Cohen, B. 2009a. Industry structure issues in the water and wastewater services sectors in Australia. Econ. Papers 29, 48-63.

Abbott, M., Cohen, B. 2009b. Productivity and efficiency in the water industry. Util. Pol. 17, 233-244

Anwandter, L., Ozuna, T. 2002. Can public sector reforms improve the efficiency of public water utilities. Env. Dev. Econ. 7, 687-700.

Aubert, C., Reynaud, A. 2005. The impact of regulation on cost efficiency: An empirical analysis of Wisconsin water utilities. J. of Prod. Analy. 23, 383-409.

Bhattacharya, A., Harris, T., Narayanan, R., Raffiee, K. 1995. Specification and estimation of the effect of ownership on the economic efficiency of the water utilities. Reg. Sci Urb. Econ. 25, 759-784.

Bottasso, A., Conti, M. (2009) Scale economies, technology and technical change in the water industry: Evidence from the English water only sector, Reg. Sci. Urb. Econ. 39, 138-147

Byrnes, J., Crase, L., Dollery B.E., Villano, R. 2010. The relative economic efficiency of urban water utilities in regional New South Wales and Victoria. Res. Ener. Econ. 32, 439-455

Coelli, T., Walding, S. 2006. Performance measurement in the Australian water supply industry: A preliminary analysis. In: Coelli, T., Lawrence, D. (Eds.) Performance Measurement and Regulation of Network Utilities. Edward Elgar, Cheltenham.

da Silva e Souza, G., Coelho de Faria, R., Belchiar, S., Moreira, T. 2007. Estimating the relative efficiency of Brazilian publicly and privately owned water utilities: A stochastic cost frontier approach. J. Amer. Wat. Res. Assoc. 43, 1237-1244.

Erbetta, F., Cave, M. 2006. Regulation and efficiency incentives: Evidence from the England and Wales water and sewerage industry. Rev. Net. Econ. 6, 425-452.

Estache, A., Trujillo, L. 2003. Efficiency effects of 'privatization' in Argentina's water and sanitation services. Wat. Pol. 5, 369-380.

Fabbri, P., Fraquelli, G. 2000. Costs and structure of technology in the Italian water industry. Empir. 27, 65-82.

Filippini, M., Hrovatin, N., Zoric', J. 2008. Cost efficiency of Slovenian water distribution utilities: An application of stochastic frontier methods. J. Prod. Analy. 29, 169-182.

Fraquelli, G., Moiso, V. 2005) Cost efficiency and economies of scale in the Italian water industry, Società Italiana di Economia Pubblica (SIEP), Dipartimento di Economia Pubblica e Territoriale - Università di Pavia, available at http://www-3.unipv.it/, accessed July 2014.

Fraquelli, G., Piacenza, M., Vannoni, D. 2004. Scope and scale economies in multiutilities: Evidence from gas, water and electricity combinations. App. Econ. 36, 2045-2057.

García-Valiñas, M.A., Muniz, M.A. 2007. Is DEA useful in the regulation of water utilities? A dynamic efficiency evaluation. App. Econ. 39, 245-252. 
Glustoff, E., Wickham, E. 1991. Negative marginal cost and disposal: Some implications for the theory of the firm. Aust. Econ. Pap. 30, 64-69.

Kirkpatrick, C., Parker, D., Zhang, Y.F. 2006. State versus private sector provision of water services in Africa: An empirical analysis. Wor. Bank Econ. Rev. 20, 143-163.

Munisamy, S. 2010. Efficiency and ownership in water supply: Evidence from Malaysia, Proceedings of the 12th International Business Research Conference, 8-9 April, Dubai, United Arab Emirates, available at http://www.wbiconpro.com/, accessed July 2014.

National Water Commission 2008. National Performance Report 2006-07 Urban Water Utilities, available at http://www.nwc.gov.au/, accessed July 2014.

National Water Commission 2009. National Performance Report 2007-08 Urban Water Utilities, available at http://www.nwc.gov.au/, accessed July 2014.

National Water Commission 2010a. National Performance Report 2008-09 Urban Water Utilities, Indicators and Definitions Handbook and Auditing Requirements, available at http://www.nwc.gov.au/, accessed July 2014.

National Water Commission 2010b. National Performance Report 2008-09 Urban Water Utilities, available at http://www.nwc.gov.au/, accessed July 2014.

Nauges, C., van den Berg, C. 2008. Economies of density, scale and scope in the water supply and sewerage sector: A study of four developing and transition economies. J. Reg. Econ. 34, 144-163.

Norman, M., Stoker, B. 1991. Data Envelopment Analysis: The Assessment of Performance. John Wiley \& Sons, Chichester NY.

Ofwat 2010a. Relative Efficiency Assessment 2007-08 Supporting Information, available at http://www.ofwat.gov.uk/, accessed July 2014.

Ofwat 2010b. Relative Efficiency Assessment 2007-08-Water Operating Expenditure Model Data, available at http://www.ofwat.gov.uk/, accessed July 2014.

Ofwat 2010c. Water and Sewerage Relative Efficiency Assessments, available at http://www.ofwat.gov.uk/, accessed July 2014.

Renzetti, S. 2001. Environmental conditions and the cost of water supply. AWRA/IWLRI/University of Dundee International Specialty Conference 2001 on Globalization and Water Resources Management, 6-8 August.

Saal, D.S., Parker, D. 2006. Assessing the performance of water operations in the English and Welsh water industry: A lesson in the implications of inappropriately assuming a common frontier. In: Coelli, T., Lawrence, D. (Eds.) Performance Measurement and Regulation of Network Utilities. Edward Elgar, Cheltenham.

Shih, J-S., Harrington, W., Pizer, W.A., Gillingham, K. 2006. Economies of scale in community water systems. J. Amer. Wat. Worl Assoc. 98, 100-108.

Thanassoulis, E. 2000. The use of data envelopment analysis in the regulation of UK water utilities: Water distribution. Eur. J. Operat. Res. 126, 436-453.

Thanassoulis, E. 2002. Comparative performance measurement in regulation: The case of English and Welsh sewerage services. J. Operat. Res. Soc. 53, 292-302.

Tupper, H.C., Resende, M. 2004. Efficiency and regulatory issues in the Brazilian water and sewage sector: An empirical study. Util. Pol. 12, 29-40.

Woodbury, K., Dollery, B.E. 2004. Efficiency measurement in Australian local government: The case of New South Wales municipal water services. Rev. Pol. Res. 21, 615-636.

Worthington A.C. 2011a. Efficiency, technology, and productivity change in Australian urban water utilities. Griffith Business School Discussion Papers in Economics, No. 2011-08.

Worthington, A.C. 2011b. Productivity, efficiency, and technological progress in Australia's urban water utilities, Waterlines Report No. 62, National Water Commission, Canberra.

Worthington, A.C. 2014. A review of frontier approaches to efficiency and productivity measurement in urban water utilities. Urb. Wat. J. 11, 55-73. 
Table 1

Sampled urban water utilities.

\begin{tabular}{|c|c|c|}
\hline Utility & Jurisdiction & Type \\
\hline ACTEW & ACT & ML \\
\hline Albury City Council & NSW & NML \\
\hline Aqwest - Bunbury Water Board & WA & NMO \\
\hline Ballina Shire Council & NSW & NMO \\
\hline Barwon Water & VIC & ML \\
\hline Bathurst Regional Council & NSW & NMO \\
\hline Bega Valley Shire Council & NSW & NMO \\
\hline Brisbane Water & QLD & ML \\
\hline Byron Shire Council & NSW & NMO \\
\hline Central Gippsland Water & VIC & MO \\
\hline Central Highlands Water & VIC & MO \\
\hline City West Water & VIC & ML \\
\hline Clarence Valley Council & NSW & NMO \\
\hline Coffs Harbour City Council & NSW & NML \\
\hline Coliban Water & VIC & MO \\
\hline Dubbo City Council & NSW & NMO \\
\hline East Gippsland Water & VIC & NML \\
\hline Gold Coast Water & QLD & ML \\
\hline Goldenfields Water & NSW & NMO \\
\hline Gosford City Council & NSW & MO \\
\hline Goulburn Valley Water & VIC & MO \\
\hline GWMWater & VIC & NML \\
\hline Hunter Water Corporation & NSW & ML \\
\hline Ipswich Water & QLD & MO \\
\hline Kempsey Shire Council & NSW & NMO \\
\hline Lismore City Council & NSW & NMO \\
\hline Logan Water & QLD & $\mathrm{MO}$ \\
\hline Lower Murray Water & VIC & NML \\
\hline MidCoast Water & NSW & NML \\
\hline North East Water & VIC & NML \\
\hline Orange City Council & NSW & NMO \\
\hline Power and Water - Darwin & NT & NML \\
\hline Power and Water - Alice Springs & NT & NMO \\
\hline Port Macquarie Hastings Council & NSW & NML \\
\hline Queanbeyan City Council & NSW & NMO \\
\hline Riverina Water & NSW & NML \\
\hline SA Water - Adelaide & SA & ML \\
\hline South East Water Ltd & VIC & ML \\
\hline South Gippsland Water & VIC & NMO \\
\hline Shoalhaven City Council & NSW & NML \\
\hline Sydney Water Corporation & NSW & ML \\
\hline Tamworth Regional Council & NSW & NMO \\
\hline Tweed Shire Council & NSW & NML \\
\hline Wannon Water & VIC & NML \\
\hline Water and Waste Services & QLD & NML \\
\hline Water Corporation - Albany & WA & NMO \\
\hline Water Corporation - Geraldton & WA & NMO \\
\hline Water Corporation - Kalgoorlie-Boulder & WA & NMO \\
\hline Water Corporation - Mandurah & WA & NML \\
\hline Water Corporation - Perth & WA & ML \\
\hline Western Water & VIC & NML \\
\hline Westernport Water & VIC & NMO \\
\hline Wingecarribee Shire Council & NSW & NMO \\
\hline Wyong Shire Council & NSW & MO \\
\hline Yarra Valley Water & VIC & ML \\
\hline
\end{tabular}

Notes: ACT Australian Capital Territory, NSW New South Wales, NT Northern Territory, QLD Queensland, SA South Australia, VIC Victoria, WA Western Australia, ML Metropolitan Large 100,000+ connected properties, MO Metropolitan Other 50-100,000 connected properties, NML Non-metropolitan Large 20-50,000 connected properties, NMO Non-metropolitan Other 10-20,000 connected properties. 
Table 2

Selected descriptive statistics.

\begin{tabular}{|c|c|c|c|c|c|c|c|}
\hline & Variable & Mean & Max. & Min. & Std. dev. & Skew. & Kurt. \\
\hline \multirow{15}{*}{ 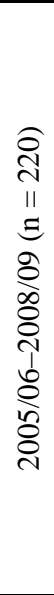 } & OXT & 35189.770 & 601724.600 & 1920.000 & 74903.750 & 4.968 & 32.095 \\
\hline & CXT & - & - & - & - & - & - \\
\hline & $\mathrm{CHC}$ & 89.705 & 100.000 & 0.000 & 21.218 & -2.857 & 11.391 \\
\hline & MBC & 95.578 & 100.000 & 0.000 & 13.805 & -4.427 & 25.785 \\
\hline & LSI & 1.607 & 12.500 & 0.260 & 1.230 & 4.290 & 33.258 \\
\hline & WQI & 25.827 & 263.158 & 0.010 & 39.318 & 2.948 & 13.351 \\
\hline & WMI & 8.637 & 92.593 & 1.075 & 9.446 & 4.441 & 33.244 \\
\hline & PRP & 127.532 & 1755.000 & 9.990 & 274.849 & 4.063 & 22.081 \\
\hline & WTR & 37396.340 & 528260.000 & 1426.000 & 79052.580 & 4.216 & 23.343 \\
\hline & PMN & 40.309 & 84.000 & 5.000 & 16.629 & 0.780 & 3.229 \\
\hline & CAP & - & - & - & - & - & - \\
\hline & BLK & 28.616 & 100.000 & 0.000 & 42.320 & 0.907 & 1.913 \\
\hline & GRD & 14.413 & 100.000 & 0.000 & 28.407 & 2.046 & 5.788 \\
\hline & REC & 3.404 & 43.428 & 0.000 & 6.289 & 3.677 & 20.256 \\
\hline & SUR & 53.388 & 100.000 & 0.000 & 41.631 & -0.220 & 1.287 \\
\hline \multirow{15}{*}{ 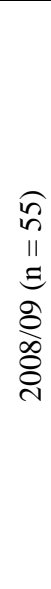 } & OXT & 38945.390 & 524745.000 & 1920.000 & 79807.490 & 4.462 & 26.309 \\
\hline & CXT & 32143.725 & 454445.389 & 410.132 & 69802.258 & 4.914 & 27.156 \\
\hline & $\mathrm{CHC}$ & 89.755 & 100.000 & 0.000 & 21.459 & -2.963 & 12.087 \\
\hline & $\mathrm{MBC}$ & 97.815 & 100.000 & 50.000 & 7.883 & -4.661 & 26.617 \\
\hline & LSI & 1.685 & 8.333 & 0.260 & 1.243 & 3.148 & 16.282 \\
\hline & WQI & 30.263 & 263.158 & 0.937 & 49.861 & 2.819 & 11.391 \\
\hline & WMI & 9.373 & 92.593 & 1.248 & 13.161 & 4.904 & 30.591 \\
\hline & PRP & 130.695 & 1755.000 & 9.990 & 281.586 & 4.032 & 21.786 \\
\hline & WTR & 36005.260 & 491968.000 & 2061.000 & 77542.600 & 4.297 & 23.826 \\
\hline & PMN & 40.550 & 84.000 & 5.460 & 16.815 & 0.792 & 3.278 \\
\hline & CAP & 689623.891 & 10433975.000 & 29256.000 & 1582023.599 & 4.979 & 17.001 \\
\hline & BLK & 30.783 & 100.000 & 0.000 & 43.337 & 0.782 & 1.698 \\
\hline & GRD & 14.520 & 100.000 & 0.000 & 27.180 & 2.033 & 5.968 \\
\hline & REC & 3.664 & 43.428 & 0.000 & 6.792 & 3.956 & 22.608 \\
\hline & SUR & 50.769 & 100.000 & 0.000 & 41.087 & -0.136 & 1.290 \\
\hline
\end{tabular}

Notes: OXT Total operating cost (\$000s), CXT Total capital cost $(\$ 000 \mathrm{~s})$, CHC Percentage of zones where chemical compliance was achieved (\%), MBC Percentage of zones where microbiological compliance was achieved (\%), LSI Inverse of real losses (L/service connection/d), WQI Inverse of water quality and service complaints (per 1,000 properties), WMI Inverse water main breaks (per $100 \mathrm{~km}$ of water main), PRP Total connected properties - water supply (000s), WTR Total urban water supplied (ML), PMN Properties served per km of water main (n), CAP Written down replacement cost of fixed water supply assets (\$000s), BLK Percentage of water sourced from bulk supplier (\%), GRD Percentage of water sourced from groundwater (\%), REC Percentage of water sourced from recycling (\%), SUR Percentage of water sourced from surface water (\%) 
Table 3

Estimated cost functions.

\begin{tabular}{|c|c|c|c|c|c|c|}
\hline \multirow[b]{2}{*}{ Variable } & \multicolumn{2}{|c|}{$\begin{array}{l}\text { Operating expenditure } \\
\text { 2005/06-2008/09 }\end{array}$} & \multicolumn{2}{|c|}{$\begin{array}{c}\text { Operating expenditure } \\
2008 / 09\end{array}$} & \multicolumn{2}{|c|}{$\begin{array}{c}\text { Capital expenditure } \\
2008 / 09\end{array}$} \\
\hline & Coef. & Std. error & Coef. & Std. error & Coef. & Std. error \\
\hline CONS. & $2.85 \mathrm{E}+05^{* * *}$ & $7.85 \mathrm{E}+04$ & $-6.10 \mathrm{E}+04$ & $3.66 \mathrm{E}+05$ & $9.20 \mathrm{E}+06^{* *}$ & $4.46 \mathrm{E}+06$ \\
\hline $\mathrm{CHC}$ & -75.008 & 151.898 & 397.240 & 2504.130 & - & - \\
\hline MBC & $579.137^{* *}$ & 270.384 & 1138.092 & 3550.244 & - & - \\
\hline LSI & 11804.460 & 9272.236 & - & - & $36145.080^{* *}$ & 16628.240 \\
\hline WQI & -273.638 & 183.248 & -119.665 & 966.062 & - & - \\
\hline WMI & 828.060 * & 484.660 & - & - & $1045.508^{*}$ & 1326.943 \\
\hline PRP & -497.313 & 903.460 & -546.242 & 705.028 & $-2687.601^{* * *}$ & 1041.254 \\
\hline WTR & 1.379 & 2.510 & - & - & $9.026^{* *}$ & 3.750 \\
\hline $.5 \times \mathrm{CHC}^{2}$ & -0.610 & 2.043 & -7.785 & 5.227 & - & - \\
\hline $.5 \times \mathrm{MBC}^{2}$ & $-8.699^{* * *}$ & 3.570 & -16.259 & 17.872 & - & - \\
\hline $.5 \times \mathrm{LSI}^{2}$ & $-517.658 *$ & 288.620 & - & - & $-6022.853^{* * *}$ & 2298.697 \\
\hline $.5 \times \mathrm{WQI}^{2}$ & $-1.323^{*}$ & 0.708 & -1.150 & 1.605 & & \\
\hline $.5 \times \mathrm{WMI}^{2}$ & $7.595^{*}$ & 4.445 & - & - & -12.590 & 18.538 \\
\hline $.5 \times \mathrm{PRP}^{2}$ & $-2.435^{* *}$ & 1.119 & 0.032 & 0.111 & $-30.266^{* * *}$ & 11.621 \\
\hline $.5 \times \mathrm{WTR}^{2}$ & $0.000^{* * *}$ & 0.000 & - & - & $-0.001^{* * *}$ & 0.000 \\
\hline $\mathrm{CHC} \times \mathrm{MBC}$ & 1.265 & 1.098 & -0.211 & 23.956 & - & - \\
\hline CHC×LSI & 1.077 & 24.058 & - & - & - & - \\
\hline CHC×WQI & $5.933^{* * *}$ & 2.048 & 5.530 & 11.671 & - & - \\
\hline CHC $\times W M I$ & -2.367 & 4.568 & - & - & - & - \\
\hline CHC×PRP & -4.091 & 3.847 & 1.744 & 6.636 & - & - \\
\hline CHC $\times W T R$ & 0.003 & 0.009 & - & - & - & - \\
\hline MBC×LSI & -66.832 & 95.938 & - & - & - & - \\
\hline $\mathrm{MBC} \times W Q I$ & 0.255 & 2.760 & -3.118 & 20.583 & - & - \\
\hline MBC $\times W M I$ & $-8.597^{*}$ & 4.653 & - & - & - & - \\
\hline $\mathrm{MBC} \times \mathrm{PRP}$ & 9.621 & 8.287 & $5.794^{*}$ & 2.577 & - & - \\
\hline MBC $\times W T R$ & -0.010 & 0.023 & - & - & - & - \\
\hline LSI×WQI & -46.699 & 30.984 & - & - & - & - \\
\hline LSI×WMI & -118.633 & 125.545 & - & - & $-1249.505^{*}$ & 646.443 \\
\hline $\mathrm{LSI} \times \mathrm{PRP}$ & -26.709 & 63.612 & - & - & 501.954 ** & 251.346 \\
\hline LSI×WTR & -0.130 & 0.198 & - & - & $-2.600^{*}$ & 1.400 \\
\hline WQI×WMI & $-9.288^{*}$ & 5.009 & - & - & - & - \\
\hline WQI×PRP & 0.638 & 1.091 & 0.470 & 0.627 & - & - \\
\hline WQI×WTR & -0.004 & 0.004 & - & - & - & - \\
\hline $\mathrm{WMI} \times \mathrm{PRP}$ & 10.369 & 18.299 & - & - & 83.019 & 76.173 \\
\hline WMI $\times W T R$ & -0.022 & 0.052 & - & - & -0.132 & 0.222 \\
\hline PRP×WTR & $0.010^{* * *}$ & 0.004 & - & - & $0.137^{* *}$ & 0.052 \\
\hline CAP & - & - & - & - & $0.115^{* * *}$ & 0.041 \\
\hline PMN & $271.688^{* * *}$ & 83.320 & 286.587 & 207.650 & - & - \\
\hline BLK & $-3097.165^{* * *}$ & 760.069 & 250.072 & 2668.655 & $-92452.080^{* *}$ & 44718.650 \\
\hline GRD & $-3106.105^{* * *}$ & 756.327 & 245.928 & 2673.185 & $-92420.640^{* *}$ & 44733.180 \\
\hline REC & $-3200.504^{* * *}$ & 745.960 & 415.026 & 2748.360 & $-92678.890^{* *}$ & 44795.400 \\
\hline SUR & $-3128.429^{* * *}$ & 754.924 & 206.572 & 2683.464 & $-92504.950^{* *}$ & 44751.500 \\
\hline Obs. & 165 & & 55 & & 55 & \\
\hline R-squared & 0.986 & - & 0.986 & - & 0.990 & - \\
\hline F-statistic & $317.342^{* * *}$ & - & $131.297^{* * *}$ & - & $173.727^{* * *}$ & - \\
\hline
\end{tabular}

Notes: CONS. Constant. All other variables as previously defined. 
Table 4

Marginal costs (MC).

\begin{tabular}{|c|c|c|c|c|c|c|c|c|}
\hline & Level & $\mathrm{MC}(\mathrm{CHC})$ & MC(MBC) & MC(LSI) & MC(WQI) & MC(WMI) & MC(PRP) & MC(WTR) \\
\hline \multirow{10}{*}{ 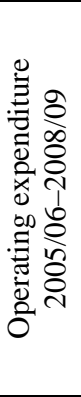 } & $50 \%$ & -166.935 & 378.188 & -17214.407 & 331.933 & -917.584 & 843.833 & -0.579 \\
\hline & $75 \%$ & -180.616 & 170.341 & -17422.390 & 323.390 & -901.184 & 766.203 & -0.956 \\
\hline & $100 \%$ & -194.298 & -37.507 & -17630.374 & 314.846 & -884.783 & 688.572 & -1.333 \\
\hline & $125 \%$ & -207.979 & -245.354 & -17838.357 & 306.303 & -868.383 & 610.942 & -1.710 \\
\hline & $150 \%$ & -221.660 & -453.201 & -18046.340 & 297.759 & -851.983 & 533.311 & -2.086 \\
\hline & $175 \%$ & -235.342 & -661.048 & -18254.323 & 289.216 & -835.582 & 455.681 & -2.463 \\
\hline & $200 \%$ & -249.023 & -868.896 & -18462.306 & 280.672 & -819.182 & 378.051 & -2.840 \\
\hline & $225 \%$ & -262.705 & -1076.743 & -18670.289 & 272.129 & -802.782 & 300.420 & -3.217 \\
\hline & $250 \%$ & -276.386 & -1284.590 & -18878.272 & 263.585 & -786.382 & 222.790 & -3.593 \\
\hline & $300 \%$ & -303.749 & -1700.285 & -19294.238 & 246.498 & -753.581 & 67.529 & -4.347 \\
\hline \multirow{10}{*}{ 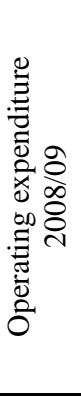 } & $50 \%$ & 25.230 & -151.200 & - & 235.389 & - & 739.542 & - \\
\hline & $75 \%$ & -149.458 & -548.792 & - & 226.690 & - & 740.573 & - \\
\hline & $100 \%$ & -324.146 & -946.384 & - & 217.990 & - & 741.604 & - \\
\hline & $125 \%$ & -498.834 & -1343.976 & - & 209.290 & - & 742.634 & - \\
\hline & $150 \%$ & -673.522 & -1741.568 & - & 200.590 & - & 743.665 & - \\
\hline & $175 \%$ & -848.210 & -2139.160 & - & 191.891 & - & 744.696 & - \\
\hline & $200 \%$ & -1022.898 & -2536.752 & - & 183.191 & - & 745.727 & - \\
\hline & $225 \%$ & -1197.586 & -2934.344 & - & 174.491 & - & 746.758 & - \\
\hline & $250 \%$ & -1372.274 & -3331.936 & - & 165.792 & - & 747.789 & - \\
\hline & $300 \%$ & -1721.650 & -4127.121 & - & 148.392 & - & 749.850 & - \\
\hline \multirow{10}{*}{ 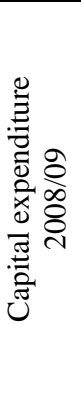 } & $50 \%$ & - & - & -44807.463 & - & 3929.703 & 4580.587 & 1.741 \\
\hline & $75 \%$ & - & - & -47345.328 & - & 3900.201 & 3591.677 & -3.534 \\
\hline & $100 \%$ & - & - & -49883.192 & - & 3870.698 & 2602.768 & -8.809 \\
\hline & $125 \%$ & - & - & -52421.057 & - & 3841.195 & 1613.858 & -14.084 \\
\hline & $150 \%$ & - & - & -54958.922 & - & 3811.693 & 624.949 & -19.359 \\
\hline & $175 \%$ & - & - & -57496.786 & - & 3782.190 & -363.961 & -24.633 \\
\hline & $200 \%$ & - & - & -60034.651 & - & 3752.688 & -1352.870 & -29.908 \\
\hline & $225 \%$ & - & - & -62572.515 & - & 3723.185 & -2341.780 & -35.183 \\
\hline & $250 \%$ & - & - & -65110.380 & - & 3693.683 & -3330.689 & -40.458 \\
\hline & $300 \%$ & - & - & -70186.109 & - & 3634.677 & -5308.508 & -51.007 \\
\hline
\end{tabular}

Notes: Level is percentage of sample mean output. All other variables as previously defined. 
Table 5

Average incremental costs (AIC).

\begin{tabular}{|c|c|c|c|c|c|c|c|c|}
\hline & Level & $\mathrm{AIC}(\mathrm{CHC})$ & AIC(MBC) & AIC(LSI) & AIC(WQI) & AIC(WMI) & AIC(PRP) & AIC(WTR) \\
\hline \multirow{10}{*}{ 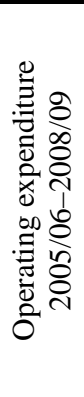 } & $50 \%$ & -158.476 & 768.231 & 3197.256 & -107.671 & 369.268 & -554.055 & 1.089 \\
\hline & $75 \%$ & -200.209 & 862.778 & -1106.346 & -24.688 & 139.872 & -337.240 & 0.944 \\
\hline & $100 \%$ & -241.943 & 957.325 & -5409.947 & 58.296 & -89.524 & -120.426 & 0.799 \\
\hline & $125 \%$ & -283.677 & 1051.872 & -9713.549 & 141.279 & -318.920 & 96.388 & 0.655 \\
\hline & $150 \%$ & -325.410 & 1146.419 & -14017.151 & 224.262 & -548.316 & 313.203 & 0.510 \\
\hline & $175 \%$ & -367.144 & 1240.966 & -18320.753 & 307.246 & -777.712 & 530.017 & 0.365 \\
\hline & $200 \%$ & -408.878 & 1335.513 & -22624.355 & 390.229 & -1007.108 & 746.831 & 0.220 \\
\hline & $225 \%$ & -450.611 & 1430.060 & -26927.957 & 473.212 & -1236.504 & 963.646 & 0.075 \\
\hline & $250 \%$ & -492.345 & 1524.607 & -31231.558 & 556.196 & -1465.900 & 1180.460 & -0.070 \\
\hline & $300 \%$ & -575.813 & 1713.701 & -39838.762 & 722.162 & -1924.692 & 1614.089 & -0.359 \\
\hline \multirow{10}{*}{ 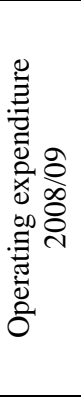 } & $50 \%$ & 409.855 & 1062.492 & - & -1.970 & - & -176.471 & - \\
\hline & $75 \%$ & 416.162 & 1024.692 & - & 56.877 & - & 8.415 & - \\
\hline & $100 \%$ & 422.470 & 986.892 & - & 115.724 & - & 193.300 & - \\
\hline & $125 \%$ & 428.777 & 949.092 & - & 174.571 & - & 378.186 & - \\
\hline & $150 \%$ & 435.085 & 911.292 & - & 233.419 & - & 563.071 & - \\
\hline & $175 \%$ & 441.392 & 873.492 & - & 292.266 & - & 747.957 & - \\
\hline & $200 \%$ & 447.699 & 835.693 & - & 351.113 & - & 932.842 & - \\
\hline & $225 \%$ & 454.007 & 797.893 & - & 409.961 & - & 1117.728 & - \\
\hline & $250 \%$ & 460.314 & 760.093 & - & 468.808 & - & 1302.613 & - \\
\hline & $300 \%$ & 472.929 & 684.493 & - & 586.503 & - & 1672.384 & - \\
\hline \multirow{10}{*}{ 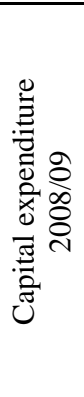 } & $50 \%$ & - & - & 13741.348 & - & 3010.360 & -397.308 & 9.896 \\
\hline & $75 \%$ & - & - & 2539.483 & - & 3992.785 & 747.839 & 10.331 \\
\hline & $100 \%$ & - & - & -8662.383 & - & 4975.211 & 1892.986 & 10.766 \\
\hline & $125 \%$ & - & - & -19864.249 & - & 5957.637 & 3038.133 & 11.201 \\
\hline & $150 \%$ & - & - & -31066.115 & - & 6940.063 & 4183.279 & 11.637 \\
\hline & $175 \%$ & - & - & -42267.980 & - & 7922.489 & 5328.426 & 12.072 \\
\hline & $200 \%$ & - & - & -53469.846 & - & 8904.914 & 6473.573 & 12.507 \\
\hline & $225 \%$ & - & - & -64671.712 & - & 9887.340 & 7618.719 & 12.942 \\
\hline & $250 \%$ & - & - & -75873.578 & - & 10869.766 & 8763.866 & 10.465 \\
\hline & $300 \%$ & - & - & -98277.309 & - & 12834.618 & 11054.159 & 14.247 \\
\hline
\end{tabular}

Notes: All variables as previously defined. 
Table 6

Product-specific (E) and ray (RAY) economies of scale.

\begin{tabular}{|c|c|c|c|c|c|c|c|c|c|}
\hline & Level & $\mathrm{E}(\mathrm{CHC})$ & $\mathrm{E}(\mathrm{MBC})$ & $\mathrm{E}(\mathrm{LSI})$ & E(WQI) & E(WMI) & $\mathrm{E}(\mathrm{PRP})$ & E(WTR) & E(RAY) \\
\hline \multirow{10}{*}{ 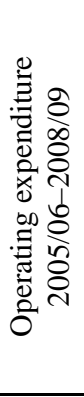 } & $50 \%$ & 0.949 & 2.031 & -0.186 & -0.324 & -0.402 & -0.657 & -1.880 & 7.476 \\
\hline & $75 \%$ & 1.108 & 5.065 & 0.064 & -0.076 & -0.155 & -0.440 & -0.988 & 12.007 \\
\hline & $100 \%$ & 1.245 & -25.524 & 0.307 & 0.185 & 0.101 & -0.175 & -0.600 & -29.701 \\
\hline & $125 \%$ & 1.364 & -4.287 & 0.545 & 0.461 & 0.367 & 0.158 & -0.383 & -4.741 \\
\hline & $150 \%$ & 1.468 & -2.530 & 0.777 & 0.753 & 0.644 & 0.587 & -0.244 & -2.253 \\
\hline & $175 \%$ & 1.560 & -1.877 & 1.004 & 1.062 & 0.931 & 1.163 & -0.148 & -1.372 \\
\hline & $200 \%$ & 1.642 & -1.537 & 1.225 & 1.390 & 1.229 & 1.975 & -0.078 & -0.940 \\
\hline & $225 \%$ & 1.715 & -1.328 & 1.442 & 1.739 & 1.540 & 3.208 & -0.023 & -0.692 \\
\hline & $250 \%$ & 1.781 & -1.187 & 1.654 & 2.110 & 1.864 & 5.299 & 0.019 & -0.533 \\
\hline & $300 \%$ & 1.896 & -1.008 & 2.065 & 2.930 & 2.554 & 23.902 & 0.083 & -0.348 \\
\hline \multirow{10}{*}{ 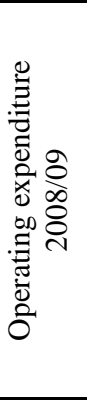 } & $50 \%$ & 16.245 & -7.027 & - & -0.008 & - & -0.239 & - & -0.568 \\
\hline & $75 \%$ & -2.784 & -1.867 & - & 0.251 & - & 0.011 & - & -0.393 \\
\hline & $100 \%$ & -1.303 & -1.043 & - & 0.531 & - & 0.261 & - & -0.179 \\
\hline & $125 \%$ & -0.860 & -0.706 & - & 0.834 & - & 0.509 & - & -0.177 \\
\hline & $150 \%$ & -0.646 & -0.523 & - & 1.164 & - & 0.757 & - & -0.146 \\
\hline & $175 \%$ & -0.520 & -0.408 & - & 1.523 & - & 1.004 & - & -0.121 \\
\hline & $200 \%$ & -0.438 & -0.329 & - & 1.917 & - & 1.251 & - & -0.101 \\
\hline & $225 \%$ & -0.379 & -0.272 & - & 2.349 & - & 1.497 & - & -0.086 \\
\hline & $250 \%$ & -0.335 & -0.228 & - & 2.828 & - & 1.742 & - & -0.073 \\
\hline & $300 \%$ & -0.275 & -0.166 & - & 3.952 & - & 2.230 & - & -0.055 \\
\hline \multirow{10}{*}{ 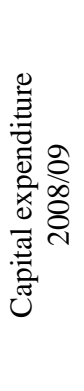 } & $50 \%$ & - & - & -0.307 & - & 0.766 & -0.087 & 5.686 & 28.427 \\
\hline & $75 \%$ & - & - & -0.054 & - & 1.024 & 0.208 & -2.923 & 39.507 \\
\hline & $100 \%$ & - & - & 0.174 & - & 1.285 & 0.727 & -1.222 & -357.388 \\
\hline & $125 \%$ & - & - & 0.379 & - & 1.551 & 1.883 & -0.795 & -20.354 \\
\hline & $150 \%$ & - & - & 0.565 & - & 1.821 & 6.694 & -0.601 & -8.796 \\
\hline & $175 \%$ & - & - & 0.735 & - & 2.095 & -14.640 & -0.490 & -5.089 \\
\hline & $200 \%$ & - & - & 0.891 & - & 2.373 & -4.785 & -0.418 & -3.361 \\
\hline & $225 \%$ & - & - & 1.034 & - & 2.656 & -3.253 & -0.368 & -2.398 \\
\hline & $250 \%$ & - & - & 1.165 & - & 2.943 & -2.631 & -0.259 & -1.803 \\
\hline & $300 \%$ & - & - & 1.400 & - & 3.531 & -2.082 & -0.279 & -1.129 \\
\hline
\end{tabular}

Notes: All variables as previously defined. 
Table 7

Product-specific (S) and global (GES) economies of scope.

\begin{tabular}{|c|c|c|c|c|c|c|c|c|c|}
\hline & Level & $\mathrm{S}(\mathrm{CHC})$ & $\mathrm{S}(\mathrm{MBC})$ & S(LSI) & S(WQI) & S(WMI) & $\mathrm{S}(\mathrm{PRP})$ & S(WTR) & GES \\
\hline \multirow{10}{*}{ 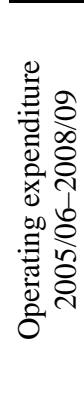 } & $50 \%$ & 0.922 & 0.848 & 0.934 & 0.904 & 0.918 & 0.805 & 0.906 & 5.397 \\
\hline & $75 \%$ & 0.898 & 0.739 & 0.924 & 0.859 & 0.890 & 0.646 & 0.864 & 5.099 \\
\hline & $100 \%$ & 0.883 & 0.609 & 0.928 & 0.816 & 0.870 & 0.450 & 0.824 & 4.800 \\
\hline & $125 \%$ & 0.875 & 0.462 & 0.943 & 0.775 & 0.855 & 0.221 & 0.786 & 4.500 \\
\hline & $150 \%$ & 0.874 & 0.297 & 0.969 & 0.734 & 0.846 & -0.040 & 0.750 & 4.196 \\
\hline & $175 \%$ & 0.879 & 0.114 & 1.005 & 0.693 & 0.842 & -0.332 & 0.715 & 3.886 \\
\hline & $200 \%$ & 0.890 & -0.084 & 1.050 & 0.653 & 0.843 & -0.653 & 0.680 & 3.570 \\
\hline & $225 \%$ & 0.907 & -0.300 & 1.104 & 0.613 & 0.848 & -1.003 & 0.647 & 3.247 \\
\hline & $250 \%$ & 0.928 & -0.532 & 1.167 & 0.572 & 0.857 & -1.383 & 0.614 & 2.914 \\
\hline & $300 \%$ & 0.985 & -1.048 & 1.318 & 0.490 & 0.886 & -2.233 & 0.547 & 2.216 \\
\hline \multirow{10}{*}{ 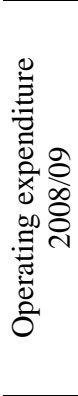 } & $50 \%$ & 2.625 & 2.908 & - & 2.374 & - & 3.230 & - & 7.868 \\
\hline & $75 \%$ & 7.293 & 8.827 & - & 5.937 & - & 10.570 & - & 21.850 \\
\hline & $100 \%$ & -28.689 & -37.723 & - & -20.700 & - & -47.996 & - & -85.900 \\
\hline & $125 \%$ & -6.951 & -9.794 & - & -4.436 & - & -13.027 & - & -20.799 \\
\hline & $150 \%$ & -4.850 & -7.219 & - & -2.755 & - & -9.913 & - & -14.507 \\
\hline & $175 \%$ & -4.222 & -6.557 & - & -2.157 & - & -9.213 & - & -12.623 \\
\hline & $200 \%$ & -4.044 & -6.492 & - & -1.880 & - & -9.275 & - & -12.088 \\
\hline & $225 \%$ & -4.079 & -6.717 & - & -1.746 & - & -9.717 & - & -12.188 \\
\hline & $250 \%$ & -4.244 & -7.131 & - & -1.690 & - & -10.414 & - & -12.678 \\
\hline & $300 \%$ & -4.855 & -8.398 & - & -1.722 & - & -12.427 & - & -14.501 \\
\hline \multirow{10}{*}{ 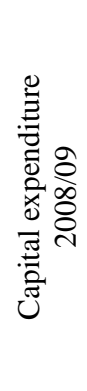 } & $50 \%$ & - & - & 1.000 & - & 0.997 & 0.974 & 0.985 & 2.976 \\
\hline & $75 \%$ & - & - & 1.001 & - & 0.995 & 0.943 & 0.969 & 2.951 \\
\hline & $100 \%$ & - & - & 1.004 & - & 0.992 & 0.900 & 0.946 & 2.918 \\
\hline & $125 \%$ & - & - & 1.008 & - & 0.989 & 0.845 & 0.918 & 2.876 \\
\hline & $150 \%$ & - & - & 1.013 & - & 0.986 & 0.778 & 0.883 & 2.826 \\
\hline & $175 \%$ & - & - & 1.019 & - & 0.983 & 0.700 & 0.843 & 2.767 \\
\hline & $200 \%$ & - & - & 1.026 & - & 0.979 & 0.609 & 0.796 & 2.700 \\
\hline & $225 \%$ & - & - & 1.034 & - & 0.974 & 0.506 & 0.743 & 2.625 \\
\hline & $250 \%$ & - & - & 1.043 & - & 0.970 & 0.392 & 0.714 & 2.541 \\
\hline & $300 \%$ & - & - & 1.066 & - & 0.960 & 0.126 & 0.548 & 2.347 \\
\hline
\end{tabular}

Notes: All variables as previously defined. 